\title{
Avanços e desafios no diagnóstico de paracoccidioidomicose causada pelo complexo de espécies da paracoccidioides: revisão integrativa
}

Advances and challenges in the diagnosis of paracoccidioidomycosis caused by the paracoccidioides species complex: integrative review

Avances y desafíos en el diagnóstico de paracoccidioidomicosis causada por el complejo de especies de paracoccidioides: revisión integradora

Jéssica Brenda de Sousa Trindade ORCID: https://orcid.org/0000-0002-4469-6033 Universidade Federal do Delta do Parnaíba, Brasil E-mail: jescatbrenda@gmail.com

Aléxia Vasconcelos Diniz

ORCID: https://orcid.org/0000-0003-4613-7611

Universidade Federal do Delta do Parnaíba, Brasil E-mail: alexiiadiniiz06@ hotmail.com

Even Herlany Pereira Alves

ORCID: https://orcid.org/0000-0001-7566-1282

Universidade Federal do Delta do Parnaíba, Brasil E-mail: evenherlany@ufpi.edu.br

Sâmylla Moita Lopes

ORCID: https://orcid.org/0000-0002-8059-9329

Universidade Federal do Delta do Parnaíba, Brasil E-mail: samylla.moita@hotmail.com

Clara Bittencourt Lima

ORCID: https://orcid.org/0000-0003-3534-3452

Universidade Federal do Delta do Parnaíba, Brasil

Email: clarbittencourt@gmail.com

Jacks Renan Neves Fernandes

ORCID: https://orcid.org/0000-0001-7868-0673

Universidade Federal do Delta do Parnaíba, Brasil E-mail: jacks.renan@ifpi.edu.br

Thayaná Ribeiro Silva Fernandes ORCID: https://orcid.org/0000-0002-6590-4620 Universidade Federal do Delta do Parnaíba, Brasil

E-mail: thayana.fernandes@ hotmail.com

Valéria de Fátima Veras de Castro

ORCID: https://orcid.org/0000-0001-8281-3029

Universidade Federal do Delta do Parnaíba, Brasi E-mail: castrovaleria701@gmail.com

Daniel Fernando Pereira Vasconcelos ORCID: https://orcid.org/0000-0002-3331-452X Universidade Federal do Delta do Parnaíba, Brasil

E-mail: prof.dr.daniel.vasconcelos@gmail.com

Lenilson do Nascimento Melo Junior

ORCID: https://orcid.org/0000-0001-8258-3753

Universidade Federal do Delta do Parnaíba, Brasil E-mail: jrdemelo01@gmail.com

\section{Resumo}

O artigo a seguir apresenta o diagnóstico clássico e alguns avanços da paracoccidioidomicose, doença infecciosa com espectro de evolução aguda, subaguda ou crônica causada pelo fungo Paracoccidioides spp., a doença é contraída através da inalação de partículas fúngicas transportadas pelo ar, tendo como principais sintomas a tosse, falta de ar, emagrecimento e lesões na pele ou mucosas. Os sintomas clínicos dificultam um diagnóstico correto, em vista da semelhança com outras doenças, como, por exemplo, a tuberculose e a sarcoidose, além de que em algumas situações pode haver um extenso período de tempo entre a exposição do indivíduo ao fungo e a manifestação dos sintomas. Levando isso em consideração, o objetivo do trabalho é avaliar e discorrer dos métodos de diagnósticos, bem como, identificar os novos avanços realizados pelos métodos moleculares, sorológicos, micológicos e histopatológicos para 
essa micose. Para esta finalidade, foram realizados uma leitura sobre estudos de casos, ensaio experimental e uma revisão sistemática.

Palavras-chave: Paracoccidioidomicose; Paracoccidioidomicose diagnóstico; Paracoccidioidomicose análise.

\begin{abstract}
The following article show the classic diagnosis and some advances in paracoccidioidomycosis, an infectious disease with a spectrum of acute, subacute, or chronic evolution caused by the fungus Paracoccidioides spp. The disease is contracted through inhalation of an airborne fungal particles, having as main symptoms, cough, shortness of breath, weight loss and skin or mucous membrane lesions. Clinical symptoms make a correct diagnosis difficult, given the similarity with other diseases, such as tuberculosis and sarcoidosis, in addition to the fact that in some situations there may be an extended period between the individual's exposure to the fungus and the manifestation of symptoms. Taking this into account, the aim of this work is to evaluate and discuss diagnostic methods, as well as identify new advances made by molecular, serological, mycological, and histopathological methods for this mycosis. For this purpose, a reading of case studies, an experimental essay and a systematic review were carried out.
\end{abstract}

Keywords: Paracoccidioidomycosis; Paracoccidioidomycosis diagnostic; Paracoccidioidomycosis analysis.

\title{
Resumem
}

El siguiente artículo presenta el diagnóstico clásico y algunos avances en la paracoccidioidomicosis, una enfermedad infecciosa con un espectro de evolución aguda, subaguda o crónica causada por el hongo Paracoccidioides spp., La enfermedad se contrae mediante la inhalación de partículas fúngicas en el aire, teniendo como principales síntomas tos, dificultad para respirar, pérdida de peso y lesiones en la piel o las membranas mucosas. Los síntomas clínicos dificultan el diagnóstico correcto, dada la similitud con otras enfermedades, como la tuberculosis y la sarcoidosis, y en algunas situaciones puede haber un período de tiempo prolongado entre la exposición del individuo al hongo y la manifestación de los síntomas. Teniendo esto en cuenta, el objetivo de este trabajo es evaluar y discutir métodos de diagnóstico, así como identificar nuevos avances realizados por métodos moleculares, serológicos, micológicos e histopatológicos para esta micosis. Para ello se realizó una lectura de casos prácticos, un ensayo experimental y una revisión sistemática.

Palabras clave: Paracoccidioidomicosis; Paracoccidioidomicosis aprobación; Paracoccidioidomicosis análisis.

\section{Introdução}

A paracoccidioidomicose (PCM) é uma micose sistêmica granulomatosa causada por fungos termodimórficos do gênero Paracoccidioides spp., descrita pela primeira vez por Adolpho Lutz em 1908, sendo considerada uma doença endêmica na América Latina (Santos, et al., 2021). A Paracoccidioides spp., foi considerado por muito tempo uma única espécie intitulada Paracoccidioides brasiliensis. Entretanto, as diferenças genéticas observadas entre os isolados e os fatores da sua grande distribuição geográfica permitiram determinar que o gênero é composto por um mesclado de espécies (Canteros, 2018) , no qual se tem, complexo Paracoccidioides brasiliensis, com os grupos genéticos PS2 (Paracoccidioides americana), PS3 (Paracoccidioides restrepiensis) e PS4 (Paracoccidioides venezuelensis), e uma nova espécie intitulada Paracoccidioides lutzii. A distribuição dos casos de PCM são heterogêneas nas diferentes regiões de cada país, ocorrendo na Venezuela, Colômbia, Argentina e no Brasil, cerca de $80 \%$ dos casos notificados ocorreram no Brasil, é endêmica nos estados de São Paulo, Minas Gerais, Rio de Janeiro, Rio Grande do Sul, Paraná, Mato Grosso e Mato Grosso do Sul, sendo uma enfermidade com incidência rural, mas nos últimos anos apresenta registros de casos em regiões suburbanas e urbanas (Martinez et al., 2017; Bernardino, et al., 2021).

O paracoccidioides spp. é um fungo que exibe características termodimórfico portanto ele se apresenta como micélio em solos férteis e rico em vegetação principalmente plantações de algodão, café e tabaco à temperatura de $25^{\circ} \mathrm{C}$ e como células leveduriforme à $37^{\circ} \mathrm{C}$ no sistema do hospedeiro (Shikanai-Yasuda, et al., 2017, Silva,. et al., 2021). A doença é adquirida através da inalação de conídios produzidos pela forma miceliana dos fungos, uma vez que eles alcançam brônquios terminais ou espaços alveolares, eles se transformam em células de levedura, que podem se espalhar através da via linfo hematogênica, afetando principalmente trabalhadores rurais do sexo masculino de meia idade, (proporção de 15-22:1 de homens afetados para 1 mulher) essa predominância pode estar relacionada ao efeito protetor do $\beta$ estradiol em mulheres, embora as mulheres possam ser facilmente infectadas, os estrogênios parecem afetar a transição do micélio para a levedura, e 
também parecem aumentar a secreção de interferon- $\gamma$ e os níveis de células Th1 e diminuir os níveis de interleucina (IL) -10 (Brito, et al., 2021).

A maioria dos indivíduos infectados não desenvolverá nenhuma doença, isso indica que esses indivíduos desenvolveram um padrão de resposta imune do tipo T-helper [Th-1] onde haverá a liberação de citocinas que irão ativar os macrófagos, células TCD4 + e TCD8 +, resultarão na formação de granulomas compactos e controle da replicação fúngica, contudo, formas dormentes do fungo ainda podem existir dentro desses granulomas, por razões não completamente estabelecidas levando a recidivas da doença. Doentes que apresentam as formas mais graves evoluem com predomínio de resposta Th2 e Th9 (Shikanai-Yasuda, et al., 2017). Esses pacientes são incapazes de formar granulomas primários que efetivamente contêm o patógeno, portanto, se espalham através da rota linfo-hematogênica para vários órgãos imediatamente após a infecção seus sinais e sintomas podem aparecerem semanas a vários meses após o primeiro contato com o fungo (Queiroz-Telles, et al., 2020).

A doença geralmente se manifesta em uma de duas formas clínicas, sendo a forma crônica (tipo adulto), responsável por cerca de $80 \%$ dos casos de paracoccidioidomicose, e ocorre principalmente em trabalhadores rurais que têm reativado fungos endógenos nos pulmões e outros órgãos na idade avançada. E a forma aguda/subaguda (tipo juvenil), que ocorre principalmente em pacientes jovens é mais grave devido ao envolvimento reticulo endotelial progressivo, levando a um alto índice de complicações, incluindo óbito (do Valle et al., 2017). A forma crônica da doença é a causadora da maioria dos casos, afetando indivíduos ontem tem seu período de incubação incerto e podendo levar meses ou anos para desenvolver após a primeira exposição do indivíduo ao fungo, o órgão mais afetado é o pulmão mais podem ser afetados a mucosa oral, as glândulas suprarrenais, o sistema nervoso, os ossos, os sintomas da doença podem ser sistêmicos ou relacionados a condições especificas de órgãos (Wagner, et al., 2021). A forma clássica é denominada aguda ou subaguda, comum em crianças e adultos jovens, apresentando uma resposta do tipo celular Th2, que não é suficiente para controlar a infecção fúngica (Hahn, et al., 2019).

O diagnóstico da paracoccidioidomicose é baseado em informações clínicas e biológicas, as investigações laboratoriais incluem estudos micológicos diretos, exames histopatológicos e o isolamento de patógenos no meio de cultura, onde são considerados o diagnóstico padrão ouro (Pinheiro, et al., 2021). O diagnóstico diferencial da paracoccidioidomicose é particularmente desafiador, pois seus sinais e sintomas clínicos, bem como os achados histopatológicos, radiológicos se assemelham a outras doenças, tais como, coccidioidomicose, histoplasmose, tuberculose, sarcoidose, dentre outras. Seu tratamento inadequado pode ter consequências prejudicais ao paciente (Wagner, et al., 2021). Tendo em vista, o presente estudo visa avaliar e demonstrar os métodos de diagnósticos, assim como, identificar os novos avanços realizados pelos métodos moleculares, sorológicos, micológicos e histopatológicos para essa micose.

\section{Metodologia}

\subsection{Estratégia de busca:}

Uma revisão integrativa foi realizada nas bases de dados, PUBMED, SCIELO, GOOGLE SCHOLAR e MEDLINE para coleta de foram utilizados estudos publicados de 2016 a 20 de setembro 2021, com os descritores específicos nos idiomas inglês, espanhol e português: "Paracoccidioidomicose", "Paracoccidioidomicose diagnóstico" e "Paracoccidioidomicose análise". 


\subsection{Critérios de inclusão:}

Foram inclusos na revisão estudos que abordassem tópicos sobre diagnósticos clínicos e laboratoriais da paracoccidioidomicose, sendo incluídos artigos originais, de língua inglesa, espanhola ou portuguesa.

\subsection{Critérios de exclusão:}

Foram excluídos trabalhos que não fossem artigos na íntegra de que se apresentavam incompletos, dissertação/teses, artigos de períodos anteriores ao proposto e trabalhos repetidos.

\subsection{Extração dos dados:}

Foi seguindo um formulário padronizado por: primeiro autor e ano de publicação, título do trabalho, metodologia utilizada, resultados encontrados e conclusão dos estudos (Brito, et al., 2016).

\section{Resultados}

A busca sistemática resultou em 44 artigos nas quatro bases de dados utilizadas (GOOGLE SCHOLAR $=4$, PUBMED = 31, SCIELO = 4, MEDLINE = 5), como indicado no fluxograma (Figura 1). Após a leitura completa, foi realizada uma segunda exclusão dos estudos que não se tratava sobre diagnostico e seus desafios. Qualquer literatura disponível relacionada ao objetivo proposto foi incluída na revisão, como revisão da literatura, ensaios experimentais, relatos de caso etc. Portanto, foram inclusos na revisão sistemática13 estudos (Tabela 1) a seleção da pesquisa foi concluída e as informações analisadas e descritas.

Figura 1. Fluxograma da revisão da literatura.
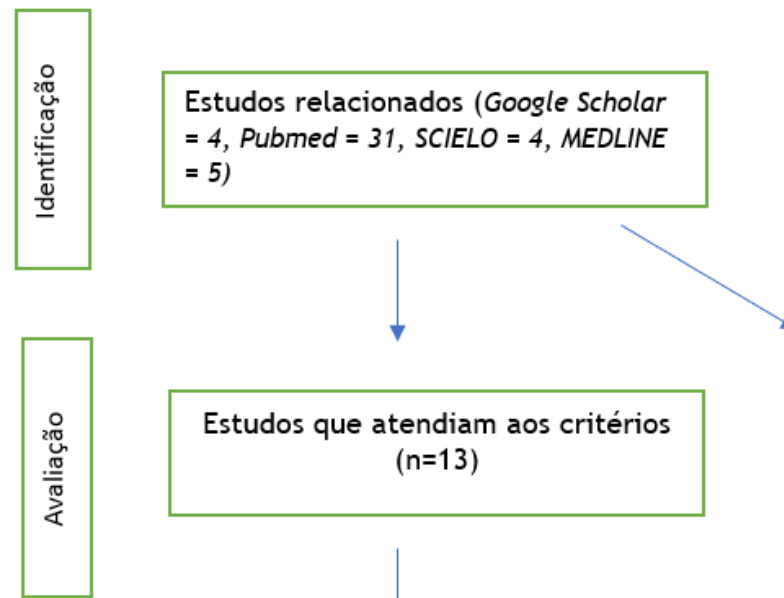

Estudos que atendiam aos critérios $(n=13)$

Foi utilizado os descritores específicos nos idiomas propostos, inglês, espanhol e português: "paracoccidioides e diagnóstico", "paracoccidioidomicose analise", "paracoccidioides spp."

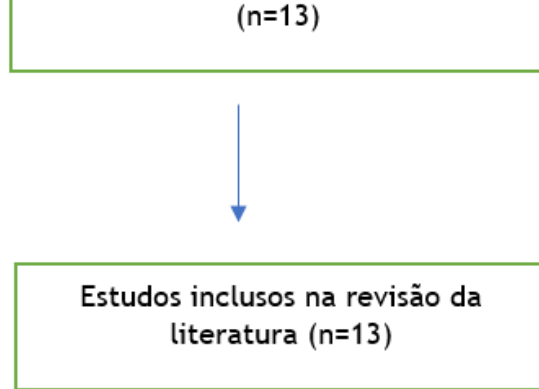

Estudos removidos por não atender aos critérios de inclusão $(n=31)$

Fonte: Autores. 
Tabela 1. Principais resultados dos estudos inclusos na revisão sistemática.

\begin{tabular}{|c|c|c|c|}
\hline Autor e Título & Método & Resultados encontrados & Conclusão \\
\hline $\begin{array}{l}\text { 1. Kamikawa, C. M. } \\
\text { et al., 2017. } \\
\\
\text { Standardization and } \\
\text { validation of Dot-ELISA } \\
\text { assay for } \\
\text { Paracoccidioides } \\
\text { brasiliensis antibody } \\
\text { detection }\end{array}$ & $\begin{array}{c}\text { Ensaio } \\
\text { experimental }\end{array}$ & $\begin{array}{l}\text { O ensaio DE mostrou sensibilidade de } 91 \% \text {, } \\
\text { especificidade de } 95,4 \% \text {, valor preditivo positivo } \\
\text { de } 96 \% \text {, negativo valor preditivo de } 98,2 \% \text {, } \\
\text { acurácia de } 93 \% \text { e grande precisão ( } \mathrm{k}=0,93 \text { ). } \\
\text { Além disso, as membranas de nitrocelulose têm } \\
\text { se mostrado viáveis para uso pelo menos } 90 \text { dias } \\
\text { após a sensibilização ao antígeno P. brasiliensis } \\
\text { B-339 }\end{array}$ & $\begin{array}{l}\text { O método Dot-ELISA foi considerado } \\
\text { uma ferramenta promissora como } \\
\text { técnica de triagem sorológica, por } \\
\text { causa de sua alta sensibilidade. Com } \\
\text { base nos presentes achados, é possível } \\
\text { afirmar que esta técnica constitui uma } \\
\text { opção marcante a ser utilizada em } \\
\text { diagnósticos de rotina para centros de } \\
\text { saúde pública. }\end{array}$ \\
\hline $\begin{array}{l}\text { 2. Buccheri, R. et al., } \\
\mathbf{2 0 1 8} . \\
\text { Case Report: Misleading } \\
\text { Serological Diagnosis of } \\
\text { Paracoccidioidomycosis } \\
\text { in a Young Patient with } \\
\text { the Acute Form Disease: } \\
\text { Paracoccidioides } \\
\text { brasiliensis or } \\
\text { Paracoccidioides lutzii? }\end{array}$ & Relato de caso & $\begin{array}{l}\text { Relato clinico de um paciente com histórico de } \\
\text { febre de } 4 \text { meses, perda de peso de } 10 \% \text {, aumento } \\
\text { generalizado dos linfonodos, anemia, na } \\
\text { tomografia computadorizada de abdome também } \\
\text { revelou grave aumento dos linfonodos resultando } \\
\text { em conglomerados com realce heterogêneo } \\
\text { delimitando áreas centrais de necrose, a } \\
\text { histopatologia de uma biópsia de linfonodo } \\
\text { cervical mostrou um processo granulomatoso } \\
\text { com necrose caseosa e múltiplas células de } \\
\text { levedura em brotamento características de } \\
\text { Paracoccidioides spp. No diagnóstico sorológico } \\
\text { foi inconclusivo, rotina anti-P.brasilliensis, o } \\
\text { teste foi repetido com uma nova amostra de soro } \\
\text { coletada } 3 \text { semanas depois e confirmou a falta de } \\
\text { reatividade contra o exoantígeno Pb113 } \\
\text { (AgPb133); no entendo o IDD realizado ao } \\
\text { mesmo tempo com antígenos livre de celular de } \\
\text { P.lutzii (AgPl208) foi fortemente positivo. Porém } \\
\text { o diagnóstico molecular relatou P. brasilliensis. }\end{array}$ & $\begin{array}{l}\text { Ao todo, nosso caso reforça a ideia de } \\
\text { uma variabilidade antigênica na } P \text {. } \\
\text { brasiliensis complexo, o que pode em } \\
\text { parte explicar alguns resultados falso- } \\
\text { negativos em pacientes com infecção } \\
\text { ativa. Verificou-se que os anticorpos } \\
\text { produzidos durante } P \text {. brasiliensis } \\
\text { infecção reconhece frações } \\
\text { antigênicas compartilhadas por ambas } \\
\text { as espécies, destacando as } \\
\text { dificuldades em distinguir as duas } \\
\text { infecções usando os ensaios } \\
\text { sorológicos de rotina atualmente } \\
\text { disponíveis. }\end{array}$ \\
\hline $\begin{array}{l}\text { 3. Kayser, M. et al., } \\
\text { 2019. } \\
\text { Chronic progressive } \\
\text { pulmonar } \\
\text { paracoccidioidomycosis } \\
\text { in a female immigrant } \\
\text { from Venezuela }\end{array}$ & Relato de Caso & $\begin{array}{l}\text { Neste relato, apresentaram o caso de uma mulher } \\
\text { de } 57 \text { anos imigrante venezuelana com PCM. Ela } \\
\text { foi inicialmente diagnosticada com sarcoidose e } \\
\text { tratada com corticosteroides, levando a uma } \\
\text { exacerbação da infecção, foi feito uma } \\
\text { reavaliação onde descartaram a doença, então um } \\
\text { novo teste para Histoplasmose e Paracoccidioides } \\
\text { foi realizado, onde o resultado por IDD foi } \\
\text { positivo para ambos. Uma nova observação } \\
\text { microscópica de elementos fúngicos foi feita e } \\
\text { qPCR a partir da biópsia pulmonar fixada em } \\
\text { formalina e fixada em parafina (FFPE) o } \\
\text { sequenciamento de ambos os amplicons de PCR } \\
\text { de amplo alcance mostrou 99,7\% permitiu o } \\
\text { diagnóstico do PCM, possibilitando um manejo } \\
\text { específico. }\end{array}$ & $\begin{array}{l}\text { Quando a infecção por PCM se torna } \\
\text { sintomática, frequentemente mimetiza } \\
\text { a sarcoidose tanto clinicamente } \\
\text { quanto na histopatologia. Portanto, } \\
\text { infecções micóticas importadas, } \\
\text { incluindo PCM, devem ser } \\
\text { consideradas como diagnósticos } \\
\text { diferenciais em pacientes originários } \\
\text { da América do Sul exibindo sintomas } \\
\text { sugestivos de sarcoidose. O } \\
\text { diagnóstico final } \\
\text { Paracoccidioidomicose, resultado este } \\
\text { concluído através da PCR (FFPE). }\end{array}$ \\
\hline $\begin{array}{l}\text { 4. Higuita-Gutiérrez. } \\
\text { L. F. et al., } 2019 . \\
\text { Metanálisis de pruebas } \\
\text { inmunológicas para el } \\
\text { diagnóstico de la } \\
\text { infección por } \\
\text { Paracoccidioides, 1972- }\end{array}$ & $\begin{array}{c}\text { Revisão } \\
\text { Sistemática }\end{array}$ & $\begin{array}{l}\text { Foram identificados } 21 \text { estudos que avaliaram } 32 \\
\text { testes diagnósticos com uma população de } 1.404 \\
\text { indivíduos saudáveis, } 2.415 \text { com outras infecções } \\
\text { e } 2.337 \text { com Paracoccidioides spp., os testes } \\
\text { analisados incluem imunodifusão, western blot, } \\
\text { ELISA, aglutinação de látex. Os testes tiveram } \\
\text { sensibilidade e especificidade superiores a } 90 \% \text {. } \\
\mathrm{Na} \text { meta-regressão por tipo de antígeno, }\end{array}$ & $\begin{array}{l}\text { A alta validade diagnóstica } \\
\text { encontrada nos testes sorológicos que } \\
\text { utilizam misturas de antígenos ou } \\
\text { gp43 purificada evidencia a } \\
\text { relevância de seu uso na clínica e em } \\
\text { programas de triagem. }\end{array}$ \\
\hline
\end{tabular}




\begin{tabular}{|c|c|c|c|}
\hline 2017 & & $\begin{array}{l}\text { constatou-se que as misturas dos antígenos e da } \\
\text { gp43 apresentaram resultados satisfatórios em } \\
\text { todos os parâmetros; por outro lado, aqueles que } \\
\text { usaram o antígeno p27 não apresentaram } \\
\text { resultados aceitáveis em nenhum dos parâmetros. }\end{array}$ & \\
\hline $\begin{array}{c}\text { 5. Moreira, A. L. E. } \\
\text { et al., 2020. } \\
\text { Immunoproteomic } \\
\text { Approach of } \\
\text { Extracellular Antigens } \\
\text { From Paracoccidioides } \\
\text { Sp cies Reveals } \\
\text { Exclusive B-Cell } \\
\text { Epitopes }\end{array}$ & $\begin{array}{c}\text { Ensaio } \\
\text { experimental }\end{array}$ & $\begin{array}{l}\text { Para identificar o perfil de antígenos secretados } \\
\text { por Paracoccidioides spp., abordagens imuno } \\
\text { proteômica foram utilizadas combinando imuno } \\
\text { precipitação, seguida de identificação do antígeno } \\
\text { por nanoUPLC-MS }{ }^{\mathrm{E}} \text { com base em proteômica. } \\
\text { Consequentemente, foi possível verificar } \\
\text { diferenças nos perfis de exoantígenos presentes } \\
\text { entre as espécies estudadas. Por meio de uma } \\
\text { abordagem de espectrometria de massa, foi } \\
\text { possível identificar } 79 \text { exoantígenos em } \\
\text { Paracoccidioides espécies. Usando ferramentas } \\
\text { de bioinformática, dois exoantígenos exclusivos } \\
\text { em P. lutzii espécies foram identificadas, bem } \\
\text { como } 44 \text { epítopos exclusivos para o } \\
\text { Paracoccidioides complexo e } 12 \text { sequências } \\
\text { antigênicas únicas que podem diferenciar entre } \\
\text { Paracoccidioides espécies. Portanto, esses } \\
\text { resultados demonstram que Paracoccidioides } \\
\text { espécies têm uma gama de epítopos de células B } \\
\text { exclusivos para o complexo, bem como } \\
\text { específicos para cada Paracoccidioides espécies. }\end{array}$ & $\begin{array}{l}\text { As diferenças entre os perfis de } \\
\text { expressão de exoantígenos foram } \\
\text { essenciais para identificar } \\
\text { biomarcadores específicos para cada } \\
\text { Paracoccidioides espécies. Além } \\
\text { disso, as análises de bioinformática } \\
\text { possibilitaram realizar uma série de } \\
\text { outras caracterizações, permitindo } \\
\text { verificar as funções biológicas, } \\
\text { homologia de exoantígenos, predição } \\
\text { de epítopos, além de fortalecer a } \\
\text { precisão dos dados. Portanto, esses } \\
\text { resultados demonstram que as } \\
\text { espécies possuem uma gama de } \\
\text { epítopos exclusivos do complexo, } \\
\text { bem como específicos para cada } \\
\text { espécie de fungo. Finalmente, os } \\
\text { testes sorológicos atuais poderiam ser } \\
\text { melhorados ainda mais com } \\
\text { combinações de dois ou mais } \\
\text { peptídeos sintéticos. }\end{array}$ \\
\hline $\begin{array}{l}\text { 6. Rodrigues, A. M. } \\
\text { et al., 2020. } \\
\text { Immunoproteomic } \\
\text { analysis reveals novel } \\
\text { candidate antigens for } \\
\text { the diagnosis of } \\
\text { paracoccidioidomycosis } \\
\text { due to Paracoccidioides } \\
\text { lutzii. }\end{array}$ & $\begin{array}{c}\text { Ensaio } \\
\text { experimental }\end{array}$ & $\begin{array}{l}\text { Nosso estudo foi realizado usando análise } \\
\text { proteômica e in sílico, onde foram capazes de } \\
\text { identificar novos antígenos que representam um } \\
\text { painel de chave para a resposta humoral contra } P \text {. } \\
\text { lutzii e P. brasiliensis. Este é o primeiro estudo a } \\
\text { relatar antígenos específicos na fase de levedura } \\
\text { da fase crítica Paracoccidioides espécies usando } \\
\text { um soro humano padrão ouro. Verificou-se que } \\
\text { proteínas hipotéticas induzem uma resposta de } \\
\text { anticorpos na PCM humana, portanto foram } \\
\text { identificadas como antígenos. }\end{array}$ & $\begin{array}{l}\text { Outros estudos empregando algumas } \\
\text { dessas proteínas nativas e } \\
\text { recombinantes serão conduzidos para } \\
\text { desenvolver um teste diagnóstico. Os } \\
\text { resultados relatados aqui fornecem } \\
\text { uma oportunidade única para o } \\
\text { refinamento das ferramentas de } \\
\text { diagnóstico desta importante micose } \\
\text { sistêmica negligenciada. }\end{array}$ \\
\hline $\begin{array}{l}\text { Comparison of clinico- } \\
\text { epidemiological and } \\
\text { radiological features in } \\
\text { paracoccidioidomycosis } \\
\text { patients regarding } \\
\text { serological classification } \\
\text { using antigens from } \\
\text { Paracoccidioides } \\
\text { brasiliensis complex and } \\
\text { Paracoccidioides lutzii. }\end{array}$ & $\begin{array}{c}\text { Ensaio } \\
\text { experimental }\end{array}$ & $\begin{array}{l}\text { Todos os } 81 \text { pacientes incluídos têm PCM } \\
\text { confirmada. Em } 57(70,4 \%) \text { deles, a confirmação } \\
\text { foi pelo exame histopatológico; em } 13(16,0 \%) \\
\text { deles, foi por exame micológico direto; e nos } \\
\text { outros } 11 \text { pacientes }(13,6 \%) \text {, foi por ambos os } \\
\text { exames. As maiores taxas da doença } \\
\text { sorologicamente compatíveis com a P. } \\
\text { brasiliensis etiologia complexa foi encontrada em } \\
\text { dois irmãos do Buriti ( } 48,2 / 100.000 \text { habitantes) } \\
\text { e Alcinópolis ( } 43,8 / 100.000 \text { habitantes), } \\
\text { enquanto as maiores taxas envolvem } P \text {. Lutzii } \\
\text { foram observados em Guia Lopes da Laguna }(9,6 \\
\text { / 100.000 habitantes) e Batayporã ( } 9,1 / 100.000 \\
\text { habitantes). }\end{array}$ & $\begin{array}{l}\text { Em conclusão, nosso estudo sugere } \\
\text { que não há diferenças nos aspectos } \\
\text { demográficos, manifestações clínicas } \\
\text { e radiológicas pulmonares, resposta } \\
\text { terapêutica e evolução da PCM } \\
\text { causada por ambos P. Lutzii ou o } P \text {. } \\
\text { complexo brasiliensis. A importância } \\
\text { desse conhecimento é a manutenção } \\
\text { das abordagens epidemiológica, } \\
\text { clínica, radiológica e terapêutica, } \\
\text { persistindo as conhecidas diferenças } \\
\text { de sensibilidade dos testes } \\
\text { sorológicos. }\end{array}$ \\
\hline $\begin{array}{l}\text { Molecular Tools for } \\
\text { Detection and } \\
\text { Identification of }\end{array}$ & $\begin{array}{c}\text { Ensaio } \\
\text { experimental }\end{array}$ & $\begin{array}{l}\text { A julgar por todos os ensaios moleculares e } \\
\text { proteômica discutidos aqui, apenas alguns testes } \\
\text { são adequados para investigar amostras clínicas } \\
\text { com o objetivo de detectar o DNA das espécies } \\
\text { de Paracoccidioides durante a infecção, e nenhum } \\
\text { deles é projetado para discriminar entre as }\end{array}$ & $\begin{array}{l}\text { A maioria das técnicas descritas aqui } \\
\text { não podem acompanhar atualizações } \\
\text { taxonômicas de Paracoccidioides, } \\
\text { principalmente por não incluir } P \text {. } \\
\text { lutzii com o sequenciamento do } \\
\text { genoma completo e sua }\end{array}$ \\
\hline
\end{tabular}




\begin{tabular}{|c|c|c|c|}
\hline $\begin{array}{l}\text { Paracoccidioides } \\
\text { Species: Current Status } \\
\text { and Future Perspectives }\end{array}$ & & $\begin{array}{l}\text { espécies crípticas descritas sobre a última década. } \\
\text { Essa armadilha pode ser devido a uma série de } \\
\text { fatores que incluem a dificuldade de coletar o } \\
\text { suficiente amostras para padronização e } \\
\text { validação, ou relacionadas à baixa carga fúngica } \\
\text { de amostras, como amostras de sangue. Além } \\
\text { disso, a natureza das amostras clínicas pode afetar } \\
\text { o resultado. Portanto, a aplicação de técnicas } \\
\text { moleculares nestes tipos de amostras pode ser } \\
\text { complicada, então os pesquisadores devem } \\
\text { escolher a dedo aquelas com qualidade atestada } \\
\text { para retrospectiva estudos. }\end{array}$ & $\begin{array}{l}\text { disponibilidade para a comunidade } \\
\text { científica, novos testes de diagnóstico } \\
\text { baseados em métodos NGS podem } \\
\text { ser uma alternativa importante, para o } \\
\text { diagnóstico. Finalmente, é essencial } \\
\text { que os pesquisadores desenvolvam } \\
\text { ensaios que podem ser usados para } \\
\text { teste de ponto de atendimento. }\end{array}$ \\
\hline $\begin{array}{l}\text { 9. Mattos, K. et al., } \\
\text { 2021. } \\
\text { An update on the } \\
\text { occurrence of } \\
\text { Paracoccidioides species } \\
\text { in the Midwest region, } \\
\text { Brazil: Molecular } \\
\text { epidemiology, clinical } \\
\text { aspects and serological } \\
\text { profile of patients from } \\
\text { Mato Grosso do Sul } \\
\text { State }\end{array}$ & $\begin{array}{c}\text { Ensaio } \\
\text { experimental }\end{array}$ & $\begin{array}{l}\text { Este estudo descritivo apresenta uma série de } \\
\text { treze casos de PCM no estado de Mato Grosso do } \\
\text { Sul, Brasil, dos quais Paracoccidioides as cepas } \\
\text { foram isoladas e genotipadas. A genotipagem } \\
\text { (tub1-PCR-RFLP) desses isolados clínicos } \\
\text { revelaram a ocorrência de três diferentes } \\
\text { Paracoccidioides espécies: P. brasiliensis sensu } \\
\text { stricto (S1), P. restrepiensis (PS3) e P. Lutzii. } \\
\text { Todos os casos de PCM descritos neste estudo (n } \\
\text { = 13) são de pacientes que vivem atualmente em } \\
\text { Mato Grosso do Sul, Brasil. Esses resultados } \\
\text { podem sugerir que as áreas endêmicas para PCM } \\
\text { estariam se expandindo a partir do Regiões Sul e } \\
\text { Sudeste para o Centro-Oeste e Norte do Brasil. } \\
\text { No entanto, outros estudos são necessários para } \\
\text { explorar esta propagação potencial. }\end{array}$ & $\begin{array}{l}\text { Assim, pela primeira vez neste } \\
\text { estado, a clínica Paracoccidioides as } \\
\text { espécies foram identificadas } \\
\text { molecularmente, em vez de a } \\
\text { identificação ser baseada em dados } \\
\text { sorológicos. Esses achados reforçam } \\
\text { a importância da identificação em } \\
\text { nível molecular das espécies de } \\
\text { fungos que ocorrem em todas as áreas } \\
\text { endêmicas. No qual poderia ser o alvo } \\
\text { principal para o melhor } \\
\text { desenvolvimento do diagnóstico e } \\
\text { acompanhamento dos pacientes com } \\
\text { PCM. }\end{array}$ \\
\hline $\begin{array}{l}\text { 10. Cruz, E. R. D. et } \\
\text { al., 2021. } \\
\text { Intestinal } \\
\text { Paracoccidioidomycosis: } \\
\text { Case report and } \\
\text { systematic review }\end{array}$ & Relato de caso & $\begin{array}{l}\text { O achado clínico mais comum foram dores } \\
\text { abdominais e perda de peso em } 31(67,3 \%) \\
\text { pacientes, em relação aos dados laboratoriais, a } \\
\text { anemia foi o achado mais comum, com média de } \\
\text { hemoglobina de } 8,8 \mathrm{~g} \text { / dL e hematócrito médio } \\
\text { de } 28,2 \% \text {. A anemia é um achado comum em } \\
\text { pacientes com a forma aguda / subaguda de } \\
\text { infecção de PCM. A histologia típica mostra } \\
\text { sinais de inflamação e granulomas ricos em } \\
\text { células epitelioides e gigantes contendo } \\
\text { quantidades variáveis de formas fúngicas. O } \\
\text { estudo anatomopatológico das biópsias do caso } \\
\text { relatado descreveu estruturas fúngicas em forma } \\
\text { de roda piloto de navio na coloração de Grocott- } \\
\text { Gomori, geralmente encontradas nesta doença. }\end{array}$ & $\begin{array}{l}\text { Sintomas que simulam doença } \\
\text { inflamatória intestinal, como dor } \\
\text { abdominal, perda de peso, diarreia e } \\
\text { sangue nas fezes, também estão } \\
\text { presentes na PCM intestinal. Na } \\
\text { revisão atual, 97,8\% dos pacientes } \\
\text { foram submetidos à biópsia do órgão } \\
\text { afetado para confirmação do } \\
\text { diagnóstico de PCM. Estudos } \\
\text { histológicos, como biópsias ou áreas } \\
\text { de ressecção cirúrgica, são } \\
\text { necessários para o diagnóstico } \\
\text { adequado. }\end{array}$ \\
\hline $\begin{array}{c}\text { Paracoccidioidomycosis } \\
\text { due to Paracoccidioides } \\
\text { brasiliensis } \mathrm{S} 1 \text { associated } \\
\text { with acquired } \\
\text { immunodeficiency } \\
\text { syndrome: A case report }\end{array}$ & Relato de caso & $\begin{array}{l}\text { Apresentamos o caso de uma paciente com } \\
\text { diagnóstico de HIV que apresentava lesões } \\
\text { cutâneas disseminadas e linfadenopatia. O } \\
\text { diagnóstico de PCM foi confirmado pelo exame } \\
\text { direto de KOH, dupla imunodifusão e isolamento } \\
\text { do fungo em amostra de abscesso em região } \\
\text { subcostal. O isolado foi identificado como } \\
\text { Paracoccidioides brasiliensis S1 por PCR } \\
\text { espécie-específica usando primers para o gene } \\
\text { GP43 (exon 2), seguido de PCR-RFLP do gene } \\
\text { alfa-tubulina. }\end{array}$ & $\begin{array}{l}\text { Existem poucos dados na literatura } \\
\text { relatando a identificação molecular } \\
\text { espécie-específica } \\
\text { Paracoccidioides em pacientes com } \\
\text { HIV / PCM. Portanto, este relato de } \\
\text { caso pode contribuir para melhorar o } \\
\text { conhecimento sobre esta doença } \\
\text { grave, suas espécies crípticas } \\
\text { causadoras e suas consequências para } \\
\text { os pacientes. }\end{array}$ \\
\hline
\end{tabular}




\begin{tabular}{|c|c|c|c|}
\hline $\begin{array}{l}\text { 12. Cocio, T. A. et al., } \\
\text { 2021. } \\
\text { Serological diagnosis of } \\
\text { paracoccidioidomycosis } \\
\text { using a Paracoccidioides } \\
\text { spp. comercial antigen } \\
\text { and the } \\
\text { counterimmunoelectroph } \\
\text { oresis method }\end{array}$ & $\begin{array}{c}\text { Estudo } \\
\text { Diagnóstico }\end{array}$ & $\begin{array}{l}\text { Todos os soros PCM ativos foram reativos } \\
\text { usando contra imune eletroforese (sensibilidade }= \\
100 \% \text { ), incluindo } 11 \text { casos de infecção por } P \text {. } \\
\text { brasiliensis e um por } P \text {. americana. Quinze } \\
\text { (88\%) de } 17 \text { soros de pacientes em tratamento ou } \\
\text { curados foram reativos, incluindo um caso de } \\
\text { infecção por } P \text {. lutzii. No gel de agarose foram } \\
\text { observadas uma a três bandas de precipitado } \\
\text { antígeno-anticorpo, com predomínio de duas a } \\
\text { três bandas no teste com soro PCM não tratado } \\
\text { ou no início da terapia antifúngica. A } \\
\text { sensibilidade geral e especificidade usando o } \\
\text { antígeno comercial e teste de dupla difusão foram } \\
75 \% \text { e } 100 \% \text {, respectivamente. }\end{array}$ & $\begin{array}{l}\text { O antígeno comercial apresentou } \\
\text { desempenho satisfatório e pode } \\
\text { contribuir para a divulgação do uso de } \\
\text { testes sorológicos para o diagnóstico } \\
\text { da PCM. }\end{array}$ \\
\hline $\begin{array}{l}\text { A New Duplex PCR- } \\
\text { Assay for the Detection } \\
\text { and Identification of } \\
\text { Paracoccidioides Species }\end{array}$ & $\begin{array}{c}\text { Ensaio } \\
\text { experimental }\end{array}$ & $\begin{array}{l}\text { Uma estratégia foi empregada para diferenciar } P \text {. } \\
\text { brasiliensis complexo e } P \text {. lutzii usando um } \\
\text { ensaio de PCR de rodada única. Avaliamos se } \\
\text { nosso ensaio de PCR duplex poderia detectar } \\
\text { seletivamente Paracoccidioides DNA de amostras } \\
\text { de solo e hospedeiros. Detectamos com sucesso a } \\
\text { amplificação positiva dos pulmões de } \\
\text { camundongos contaminados com } \\
\text { Paracoccidioides spp. Leveduras, indicando o } \\
\text { uso potencial de fragmentos de tecido fresco para } \\
\text { detectar Paracoccidioides. Uma diluição de } 10 \\
\text { vezes foi usada para avaliar a capacidade do } \\
\text { nosso ensaio de detectar Paracoccidioides DNA } \\
\text { na presença de DNA no solo. }\end{array}$ & $\begin{array}{l}\text { Ainda há apenas um número limitado } \\
\text { de métodos de impressão digital } \\
\text { baseados em DNA disponíveis para } \\
\text { tipagem de espécies recém-descritas. } \\
\text { Portanto, para fins de diagnóstico, a } \\
\text { estratégia usada aqui para diferenciar } \\
P \text {. brasiliensis complexo e } P \text {. lutzii } \\
\text { facilita a interpretação dos resultados } \\
\text { e minimiza os erros apresentados por } \\
\text { outros testes que geram } \\
\text { caracterizações duvidosas, requerem } \\
\text { múltiplas etapas e / ou são caros para } \\
\text { o diagnóstico de uma doença } \\
\text { negligenciada que ocorre } \\
\text { principalmente em países de renda } \\
\text { média alta. }\end{array}$ \\
\hline
\end{tabular}

Fonte: Autores.

\section{Discussão}

A técnica para o diagnóstico laboratorial de infecções fúngicas consiste no exame microscópico direto de espécimes clínicos e sua cultura seguida de observação macroscópica e microscópica das colônias para a identificação das espécies fúngicas. No entanto, a identificação precisa do microrganismo por meio de cultura tem seu crescimento lento, a maioria das colônias aparecem entre a terceira e quarta semana de cultivo. Histologicamente, a coloração é feita utilizando coloração de Grocott-Gomori e o método de ácido periódico Schiff (PAS), o que permite a visualização de múltiplos brotamentos de filhos ligados à mãe, resultando em uma aparência semelhante à de "orelhas de Mickey Mouse" ou de "leme de marinheiro" (Sousa, J. A. et al., 2021). A detecção de anticorpos por imunodifusão dupla (IDD), imunoblots (IB), contraimunoeletroforese (CIE) e ensaio imunoenzimático (ELISA) estão disponíveis em laboratórios de referência para o diagnóstico de P. brasiliensis, com IDD sendo utilizado com mais frequência. Métodos típicos de identificação em amostras clínicas ou cultura não são capazes de diferenciar P. brasiliensis de P. lutzii, neste ponto a genotipagem é necessária para fazê-lo (Costa, et al. 2019). O crescente desenvolvimento da biologia molecular trouxe novos testes para diagnóstico de PCM, que se baseiam principalmente em PCR e PCR-RFLP. Essas técnicas moleculares ainda estão em busca de melhores alvos que permitam a padronização e aplicação com parâmetros de precisão adequados (Nery, et al., 2021).

Higuita-Gutiérrez, et al., (2019) realizaram uma meta análise dos testes imunológicos, pois eles têm sido muito utilizados como um método alternativo para diagnóstico da PCM, podendo além de analisar, monitorar a evolução da doença e sua resposta frente ao tratamento. São meios mais simples e baratos do que os testes moleculares, o que ajudará em sua 
implementação. Os principais testes imunológicos incluem imunodifusão em gel de ágar (IDGA), imunofluorescência indireta, testes de ELISA, Immunoblotting e Western Blot. Nestes testes, existem diferenças significativas na obtenção de antígenos e preparações de antígenos de misturas de antígenos brutos, parcialmente purificados como gp43, o que pode ter um impacto no desempenho diagnóstico, especialmente devido a reações cruzadas com outros microrganismos. (Kamikawa, et al., 2017) relataram que imunodifusão dupla (IDD) é o método utilizado para diagnosticar a Paracoccidioides spp. A detecção de IDD é específica, mas sua sensibilidade varia de $65 \%$ a 100\%, dependendo da preparação do antígeno utilizado, apesar de ser um método muito utilizado, é necessário a implementação de um teste mais rápido, diante disso os autores avaliaram o ensaio DOT-ELISA, onde se demonstrou ser um meio apropriado para a deteç̧ão de anticorpos ou antígenos, no qual os fatos comprovam que além de pontual é muito favorável e versátil, podendo ser usado como teste de triagem sorológica, pois apresenta uma alta sensibilidade, permitindo que resultados negativos sejam emitidos em um tempo menor que o teste IDD, o que tem grande valor diagnóstico, principalmente por excluir a suspeita clínicas da paracoccidioidomicose.

Kayser, et al., (2019) apresentaram um relato clínico onde a paciente emigrante venezuelana foi inicialmente diagnosticada com sarcoidose devido à combinação de sintomas respiratórios e achados radiológicos e histológicos. A diferenciação entre essas doenças pode ser um desafio devido às semelhanças clínicas e histopatológicas (Abreu, et al., 2017). As manifestações clínicas, além dos dados epidemiológicos, devem ser exaustivamente coletadas, pois podem auxiliar no diagnóstico da doença, o uso de colorações fungicidas específicas, cultura, exames histopatológicos de amostras clínicas obtidas de lesões suspeitas e sorologia devem ser realizados para confirmação do diagnóstico clínico (Merino-Alado, et al., 2020). Após um reexame da biópsia pulmonar, verificou-se a detecção de partículas Groccot positivas intracelulares acompanhadas de pneumonia de células gigantes, sugestiva de infecção por fungos, manchas iniciais mostraram pequenas leveduras mais alinhadas com histoplasmose, o teste sorológico foi realizado para histoplasmose usando métodos de imunodifusão dupla (IDD) bem como para paracoccidioidomicose (IDD), os anticorpos histoplasma e paracoccidioides foram detectados por IDD. Uma desvantagem da sorologia é a potencial reatividade cruzada entre o anti-P. anticorpos brasiliensis com antígenos de outros fungos, principalmente com a Histoplasma capsulatum, devido ao uso frequente de preparações brutas de microrganismos inteiros, contendo antígenos indefinidos com alta variabilidade (Shikanai-Yasuda, et al., 2017). Em visto disso, foi realizado um ensaio de qPCR a partir da biópsia pulmonar fixada em formalina e fixada em parafina (FFPE) o sequenciamento de ambos os amplicons de PCR de amplo alcance mostrou 99,7\% de identidade de pares com sequências de Paracoccidioides brasiliensis como o patógeno causador, já o PCR específico para histoplasma não amplificou o DNA. Concluindo que a paciente apresentava paracoccidioidomicose, conforme sugerido pela detecção de anticorpos, e PCR da FFPE.

Cruz, et al., (2021), expuseram na sua revisão relatos de casos de pacientes afetados pela paracoccidioidomicose com envolvimento do trato gastrointestinal onde pode afetar qualquer parte do sistema digestivo, sendo a localização mais comum da doença o cólon, seguido do intestino delgado e boca. Os sintomas mais comuns encontrados são dores abdominais, perda de peso e diarreia, (sintomatologia encontrada em pacientes com diagnóstico de doença inflamatória intestinal). Nesta revisão alguns pacientes desenvolveram uma síndrome clínica que assimilava a doença de Crohn (DC), apresentando colonoscopias com múltiplas úlceras de cólon superficiais ou profundas intercaladas por áreas com mucosa normal. Essas informações destacam a importância dos exames endoscópicos e das biópsias para o diagnóstico adequado das úlceras intestinais. A paracoccidioidomicose é uma doença fúngica que pode assemelhar-se às manifestações da doença de Crohn em pacientes de países endêmicos, uma vez que esta condição auto inflamatória crônica pode afetar qualquer parte do trato digestivo. Sendo assim, os pesquisadores sugerem que a PCM intestinal deve ser considerada como um diagnóstico diferencial para doença inflamatória intestinal em áreas endêmicas (Lomazi, et al., 2018). 
Buccheri, et al., (2018) demonstraram um relato de caso em que o paciente foi diagnosticado com a forma aguda (FA) da $P$. brasiliensis, porém 21 dias do início do tratamento o paciente fez uma triagem de rotina que acabou tendo resultados inconclusivos para $P$. brasiliensis anticorpos, entretanto teve resultados positivos com $P$. lutzii antígenos. É comum ter resultados negativos na triagem sorológica de rotina com pacientes portadores da PCM, essas falhas de deteção de antiParaoccidioides anticorpos é possível estar relacionados a técnicas sorológicas ou ao estado da reatividade imunológica do hospedeiro. Uma das hipóteses relatadas pelos os autores é que como a reatividade IDD é baseada principalmente no reconhecimento de gp43 e porque diferentes isolados podem produzir diferentes isoformas de gp43, essas isoformas podem não ser reconhecidas em ensaios sorológicos que usam antígenos solúveis, como o IDD, mas não interferem em ensaios que usam antígenos ligados à membrana, como o IB. Com os resultados obtidos os pesquisadores reforçam a ideia que existe uma variabilidade antigênica na $P$. brasilliensis complexo, o que pode em partes explicar alguns resultados falso-negativo, eles também sugerem que os anticorpos produzidos durante a $P$. brasiliensis infecção reconhece frações antigênicas compartilhadas por ambas as espécies. Para concluir o diagnóstico um ensaio de reação (PCR) foi realizado usando iniciadores previamente projetados a partir do P. brasiliensis sequência gp43. Identificação da espécie como P. brasiliensis foi ainda confirmado por sequenciação dos produtos de amplificação.

Conforme Pereira, et al., (2020) pacientes com perfil sorológico sugestivo de P. Lutzii e pacientes com perfil sorológico indicativo de $P$. brasiliensis, apresentam as mesmas manifestações clínicas, radiológicas, resposta terapêutica e evolução da PCM. Para a identificação de espécies de paracoccidioides, o padrão de referência é realizado por métodos moleculares de isolados clínicos em cultura, mas o crescimento de Paracoccidioides spp., em meios de cultura é muito demorado e os métodos moleculares não estão disponíveis no laboratório clínico de rotina, eles estão mais presentes em centros de estudos, portanto o mais indicado a se usar é a sorologia como estratégia para presumir a espécie causadora da PCM. Os autores relataram que a principal característica bioquímica que diferencia $P$. Lutzii de $P$. brasiliensis complexo é a ausência de expressão de gp43. (Cocio, et al., 2021) esclareceram no seu estudo que a glicoproteína gp43 é o principal componente antigênico da Paracoccidioides spp., mas sua produção varia entre os isolados de fungos, particularmente em $P$. lutzii, cuja gp43 é liberada em quantidades menores ou ausente e ter a estrutura molecular alterada.

Moreira, et al., (2020) evidenciaram que a imunoproteômica é considerada uma ferramenta poderosa para a identificação de antígenos, além do mais, os antígenos são moléculas reconhecidas pelo sistema imunológico, tornando-se excelentes alvos para testes diagnósticos de doenças causadas por microrganismo, diante disso, foi possível investigar quais antígenos são secretados por espécies que representam Paracoccidioides complexo. Além de tudo, essas análises permitiram a identificação de excelentes candidatos a biomarcadores para triagem epidemiológica, diagnóstico, acompanhamento de pacientes. Observou-se que é possível verificar diferenças nos perfis de exoantígenos entre as espécies, essas diferenças são essenciais para identificar biomarcadores específicos para cada Paracoccidioides espécies, também foi possível identificar exoantígenos exclusivos da $P$. lutzii. Os estudiosos também utilizaram as análises de bioinformática para realizar uma série de outras caracterizações, permitindo verificar as funções biológicas, homologia de exoantígenos, predição de epítopos, e tendo dados mais precisos. Consequentemente novas análises estão em andamento para verificar o potencial dessas moléculas, que podem ser usados no desenho de um teste diagnóstico rápido para PCM, como demonstra o estudo feito por Rodrigues, et al., (2020) que da mesma forma investigaram através de uma abordagem de imunoproteômica antígenos associados a paracoccidioides, onde utilizaram a detecção imunológica usando o soro humano e a análise de espectrometria de massa, diante desse estudo puderam identificar um número de proteínas altamente imunorreativas identificadas em P. lutzii e P. brasilliensis, das proteínas identificadas, a maioria está envolvida nas vias metabólicas, metabolismo do carbono e biossíntese de metabólitos secundários em ambos imunoproteoma, sendo o primeiro trabalho a relatar antígenos específicos na fase de 
levedura, usando o soro humano. Essas novos proteomas imunológicos de Paracoccidioides serão usados para desenvolver vacinas e testes diagnósticos em locais sensíveis e acessíveis que identifique efetivamente o hospedeiro infectado pela PCM.

Cocio, et al., (2021) utilizaram no seu estudo a contraimunoeletroforese e imunodifusão dupla (IDD) para avaliar o antígeno comercial de Paracoccidioides spp., onde foram reagentes em soros de casos de PCM e pacientes com outras doenças. O Antígeno ID de Paracoccidioides spp., reagente é um lisado de levedura de uma cepa não identificada de Paracoccidioides spp., que contém a glicoproteína gp43 e é indicada para uso em teste sorológico de imunodifusão em gel para o diagnóstico de PCM, mostrando uma sensibilidade geral de 75\% com soro PCM, este antígeno também é adequado contraimunoeletroforese. Pode-se verificar até três bandas precipitadas no teste com soro PCM sugere que Paracoccidioides ID Antigen, contém pelo menos três moléculas antigênicas que reagem com diferentes anticorpos produzidos pelos pacientes. É interessante que o antígeno comercial avaliado reagiu com soros de pacientes cuja PCM foi causada por P. brasiliensis, $P$. americana e $P$. lutzii. Este estudo demonstrou uma baixa taxa de reação cruzada com imunodifusão usando soros de pacientes com histoplasmose e aspergilose. Antígenos disponíveis comercialmente podem tornar o diagnóstico sorológico da paracoccidioidomicose mais amplamente disponível dos locais distantes dos centros de pesquisas.

Pinheiro, et al., (2020) exploraram e destacaram que a taxonomia dos agentes da PCM sofreu várias alterações desde o descobrimento da doença, impulsionado pela grande diversidade morfológica e características genéticas divergentes de alguns isolados. Essas variações se intensificaram nos últimos anos com a introdução de métodos de características moleculares para a designação genética do fungo, como análise de sequenciamento multilocus ou análise de sequenciamento do genoma completo. Vários métodos baseados em PCR podem detectar polimorfismos no DNA de paracoccidioides e, assim, auxiliar na identificação das espécies, como por exemplo a técnica do polimorfismo de comprimento de fragmento de limitação (RFLP) que pode ser combinado com uma técnica de PCR convencional, para que a restrição enzimática ocorra após a amplificação do DNA diretamente no amplicon, aumentando o número de cópias nas quais as endonucleases podem atuar. (Mattos, et al., 2021) identificaram molecularmente as espécies da Paracoccidioides pela primeira vez no estado do Mato Grosso do Sul, onde seus isolados clínicos foram obtidos e seus DNAs genômicos foram submetidos à genotipagem por tubl-PCR-RFLP, no qual foram coletados de diferentes fontes, tais como, fragmentos de lesão de pele, raspagens de lesão oral, aspirados de linfonodo, aspiração traqueal e escarros; esses isolados clínicos de pacientes com PCM foram genotipadas para determinar suas espécies filogenéticas, eles também apresentaram o primeiro relato de P. restrepiensis (PS3).

Peçanha, et.al., (2021) apresentaram um relato de caso onde o paciente era portador do HIV positivo que evidenciava lesões cutâneas disseminadas e linfadenopatia generalizada, além de acometimento respiratório e do sistema nervoso central, teve seu diagnóstico de PCM confirmado pelo exame direto de $\mathrm{KOH}$, dupla imunodifusão e isolamento do fungo em amostra de abscesso em região subcostal, seu isolado foi identificado como Paracoccidioidomicose brasiliensis por PCR usando primers para o gene codificador de proteínas GP43 (exon2) seguido por PCR-RFLP do gene alfa-tubulina. A grande maioria dos ensaios de base molecular é aplicada a paracoccidioides que são isolados em culturas. O gene GP43 é um dos principais marcadores usados para técnicas moleculares e faz parte do DNA nuclear (Pinheiro, et al., 2020). A paracoccidioidomicose em hospedeiros imunocompetentes pode se apresentar com duas formas clínicas: aguda/ subaguda e crônica. No entanto, os achados clínicos relacionados à PCM em pacientes infectados pelo HIV mostram que as formas aguda e crônica da doença podem ocorrer simultaneamente, podendo aumentar a gravidade clínica dos pacientes com a coinfecção por HIV/PCM.

Tanto o estudo feito por Mattos, et al., (2021) como o relato de caso de Peçanha, et.al., (2021) eles corroboram com o estudo feito por Roberto, et al., (2015) onde ele demostra que Tub1-RFPL pode diferenciar eficientemente entre as espécies da Paracoccidioides com alta precisão, também se recomenda a inclusão de pelo menos uma reação RFLP de controle positivo de uma cepa de referência, pois esse método apresenta uma alternativa aos esquemas de tipagem de sequencias multilocus. Os 
autores concordam que a Tub1-RFLP também pode ser uma ferramenta útil para a verificação de número de isolados de paracoccidioides maiores para estudos epidemiológicos.

No estudo de Pinheiro, et al., (2021) um ensaio de PCR duplex que foi desenvolvido para detectar e diferenciar simultaneamente entre os membros do P. brasilliensis complexo e $P$. lutzii, este ensaio apresentou boas vantagens, tais como, alta especificidade e sensibilidade para Paracoccidioides espécies, a possibilidade de detectar duas espécies em uma única reação (por exemplo, qualquer membro do $P$. brasiliensis complexo junto com $P$. lutzii), demonstrando, culturas mistas em isolamento primário ou coinfecção putativa diretamente de amostras clínicas, abrindo novas oportunidades de diagnóstico e os principais fatores potencialmente implicados na etiopatogênese da PCM. Um marco forte do estudo é a primeira descrição sobre infecções mistas em humanos, consistindo de ambos $P$. brasiliensis e $P$. lutzii revelado em uma ampla gama de órgãos dos pacientes com PCM. A estratégia molecular usada neste ensaio para investigar tecidos FFPE permite a diferenciação de $P$. brasiliensis complexo e P. lutzii. Não obstante, destacamos que não é possível discriminar membros do $P$. brasiliensis (S1, PS2, PS3 e PS4) por eletroforese em gel, pois os amplicons têm o mesmo tamanho (ou seja, 308 bp), apoiando assim o uso de sequenciamento de DNA para identificação até o nível de espécie, esses achados são relevantes para o ponto de vista epidemiológico pois permite reconhecer e estimar a frequência de infecções mistas em países da América do Sul.

\section{Conclusão}

É interessante notar que todos os estudos analisados aqui evidenciaram consistência sobre compreensão e manejo clínico dessa enfermidade. O perfil molecular apresentou-se bem-sucedido, pois foi essencial para a conclusão de um diagnóstico inconclusivo. Um estudo adicional com mais foco na área é, portanto, sugerido. As evidências revisadas aqui parecem sugerir um papel pertinente dos testes de IDD para triagem e acompanhamento clínico. Também alusivos aos testes de imunodifusão e imunoeletroforese. Permanecem vários aspectos sobre o Dot-Elisa que o frisam promissor no sorodiagnóstico por sua alta sensibilidade. A literatura atual sobre o tema presta atenção de como esta técnica constitui uma opção extraordinária para a confirmação fúngica. Assim, a importância da imunoproteômica para investigação de novos antígenos permitem expandir o uso da sorologia da PCM. Outro aspecto significativo veio da utilização da PCR, notável quando há um diagnóstico duvidoso na sorologia, com meios para uma análise mais precisa. Todos os estudos revisados até agora, sofrem com a ausência de mais dados que corroborem para a informação do diagnóstico da PCM. Todos os métodos mencionados anteriormente sofrem com a indisponibilidade de material e pessoal técnico em áreas remotas.

Apesar dessas limitações, esta revisão fornece uma oportunidade única para melhorar as ferramentas de diagnóstico para esta importante micose sistêmica negligenciada. Portanto, as exibições neste estudo têm várias implicações práticas em futuras pesquisas: caracterização dos exoantígenos, a busca de novos biomarcadores e a exploração de novas metodologias de fácil manejo.

\section{Referências}

Abreu, M. A. M. M. D., Lastória, J. C., Mattos, A. L. D. A., \& Alchorne, M. M. D. A. (2017). Paracoccidioidomycosis with sarcoid-like lesions: a diagnostic challenge. Revista da Sociedade Brasileira de Medicina Tropical, 50, 273-276. https://doi.org/10.1590/0037-8682-0246-2016

Bernardino, P. M., Azarias, A. C. F., dos Santos, F. G. J., Braga, A., \& Junior, W. C. (2021). Paracoccidiomicose juvenil: um relato de caso. Revista Eletrônica Acervo Saúde, 13(2), e5953-e5953. https://doi.org/10.25248/reas.e5953.2021

Benard, G., Costa, A. N., Leopércio, A. P. S., Vicentini, A. P., Kono, A., \& Shikanai-Yasuda, M. A. (2013). Chronic paracoccidioidomycosis of the intestine as single organ involvement points to an alternative pathogenesis of the mycosis. Mycopathologia, 176(5), 353-357. https://doi.org/10.1007/s11046-013-9699Z.

Brito, T. G. N. D., Taborda, M., Provenci, B., Costa, A. N., \& Benard, G. (2021). A Case-Control Study of Paracoccidioidomycosis in Women: The Hormonal Protection Revisited. Journal of Fungi, 7(8), 655. https://doi.org/DOI: 10.3390/jof7080655 
Brito, L. F. N. de et al., (2016). Influência do tratamento ortodôntico na reabsorção radicular: uma revisão sistemática. RFO UPF, v. 21 , n. 2, p. $231-236$.

Buccheri, R., dos Santos Morais, V., Kamikawa, C. M., Vidal, M. S. M., Naves, G., Del Negro, G. M. B., ... \& Benard, G. (2018). Case Report: Misleading Serological Diagnosis of Paracoccidioidomycosis in a Young Patient with the Acute Form Disease: Paracoccidioides brasiliensis or Paracoccidioides lutzii?. The American journal of tropical medicine and hygiene, 98(4), 1082. https://doi.org/10.4269/ajtmh.17-0812

Canteros, C. E. (2018). Paracoccidioidomicosis: crónica de una enfermedad olvidada. Revista Medicina, 78(3).

Cocio, T. A., \& Martinez, R. (2021). Serological diagnosis of paracoccidioidomycosis using a Paracoccidioides spp. comercial antigen and the counterimmunoelectrophoresis method. The Brazilian Journal of Infectious Diseases, 25(5), 101607. https://doi.org/10.1016/j.bjid.2021.101607

Costa, A. F. P., Dos Santos, V. M., Leite, M. R., \& de Farias Filho, F. T. (2019). A Brazilian male with typical oral and pulmonary paracoccidioidomycosis. Medical journal of the Islamic Republic of Iran, 33, 145. https://doi.org/10.34171/mjiri.33.145

Cruz, E. R. D., Forno, A. D., Pacheco, S. A., Bigarella, L. G., Ballotin, V. R., Salgado, K., ... \& Soldera, J. (2021). Intestinal Paracoccidioidomycosis: Case report and systematic review. Brazilian Journal of Infectious Diseases, 25. https://doi.org/10.1016/j.bjid.2021.101605

do Valle, A. C. F., de Macedo, P. M., Almeida-Paes, R., Romão, A. R., dos Santos Lazéra, M., \& Wanke, B. (2017). Paracoccidioidomycosis after highway construction, Rio de Janeiro, Brazil. Emerging infectious diseases, 23(11), 1917. https://doi.org/10.3201/eid2311.170934

Hahn, R. C., Rodrigues, A. M., Della Terra, P. P., Nery, A. F., Hoffmann-Santos, H. D., Gois, H. M., ... \& de Camargo, Z. P. (2019). Clinical and epidemiological features of paracoccidioidomycosis due to Paracoccidioides lutzii. PLoS neglected tropical diseases, $13(6)$, e007437. https://doi.org/10.1371/journal.pntd.0007437

Higuita-Gutiérrez, L. F., Quintero-Quinchía, C., Madera-Miranda, I. C., \& Cardona-Arias, J. A. (2019). Metanálisis de pruebas inmunológicas para el diagnóstico de la infección por Paracoccidioides, 1972-2017. Infectio, 23(2), 167-174. https://doi.org/10.22354/in.v23i2.774

Kamikawa, C. M., Mendes, R. P., \& Vicentini, A. P. (2017). Standardization and validation of Dot-ELISA assay for Paracoccidioides brasiliensis antibody detection. Journal of Venomous Animals and Toxins including Tropical Diseases, 23. https://doi.org/10.1186/s40409-017-0101-3

Kayser, M., Rickerts, V., Drick, N., Gerkrath, J., Kreipe, H., Soudah, B., ... \& Suhling, H. (2019). Chronic progressive pulmonary paracoccidioidomycosis in a female immigrant from Venezuela. Therapeutic advances in respiratory disease, 13, 1753466619894913. https://doi.org/10.1177/1753466619894913

Lomazi, E. A., de Negreiros, L. M. V., Magalhães, P. V. V. S., Togni, R. D. C. S., de Paiva, N. M., Ribeiro, A. F., \& Leal, R. F. (2018). Intestinal paracoccidioidomycosis resembling Crohn's disease in a teenager: a case report. Journal of medical case reports, 12(1), 1-4. https://doi.org/10.1186/s13256$018-1641-\mathrm{z}$

Martinez, R. (2017). New trends in paracoccidioidomycosis epidemiology. Journal of fungi, 3(1), 1. https://doi.org/10.3390/jof3010001

Mattos, K., Cocio, T. A., Chaves, E. G. A., Borges, C. L., Venturini, J., de Carvalho, L. R., ... \& Weber, S. S. (2021). An update on the occurrence of Paracoccidioides species in the Midwest region, Brazil: Molecular epidemiology, clinical aspects and serological profile of patients from Mato Grosso do Sul State. PLoS neglected tropical diseases, 15(4), e0009317. https://doi.org/10.1371/journal.pntd.0009317

Merino-Alado, R., Pineda, J., Rasquin, J. H., Landaeta, M. E., \& Mata-Essayag, S. (2020). Granulomatous mastitis due to coinfection with Histoplasma sp. and Paracoccidioides sp.: A case report. Medical mycology case reports, 27, 52-54. https://doi.org/10.1016/j.mmcr.2020.01.006

Moreira, A. L. E., Oliveira, M. A. P., Silva, L. O., Inácio, M. M., Bailão, A. M., Parente-Rocha, J. A., ... \& Borges, C. L. (2020). Immunoproteomic approach of extracellular antigens from Paracoccidioides species reveals exclusive B-cell epitopes. Frontiers in microbiology, 10 , 2968. https://doi.org/10.3389/fmicb.2019.02968

Nery, A. F., de Camargo, Z. P., Rodrigues, A. M., Portela, T. F., Hoffmann-Santos, H. D., Pinheiro, B. G., ... \& Hahn, R. C. (2021). Puzzling paracoccidioidomycosis: Factors associated with the severity of Paracoccidioides lutzii infections. International Journal of Infectious Diseases, 107, 284-290. https://doi.org/10.1016/j.ijid.2021.05.002

Peçanha, P. M., Bahiense, I. C., Kruschewsky, W. L. L., Biasutti, C., Júnior, C. U. G. F., Pinheiro, B. G., ... \& Gonçalves, S. S. (2021). Paracoccidioidomycosis due to Paracoccidioides brasiliensis S1 associated with acquired immunodeficiency syndrome: A case report. Revista Iberoamericana de Micología, 38(1), 5-8. https://doi.org/10.1016/j.riam.2020.09.003

Pereira, E. F., Gegembauer, G., Chang, M. R., Camargo, Z. P. D., Nunes, T. F., Ribeiro, S. M., ... \& Paniago, A. M. (2020). Comparison of clinicoepidemiological and radiological features in paracoccidioidomycosis patients regarding serological classification using antigens from Paracoccidioides brasiliensis complex and Paracoccidioides lutzii. PLoS neglected tropical diseases, 14(8), e0008485. https://doi.org/10.1371/journal.pntd.0008485

Pinheiro, B. G., Pôssa, A. P., Della Terra, P. P., de Carvalho, J. A., Ricci, G., Nishikaku, A. S., ... \& Rodrigues, A. M. (2021). A New Duplex PCR-Assay for the Detection and Identification of Paracoccidioides Species. Journal of Fungi, 7(3), 169. https://doi.org/10.3390/jof7030169

Pinheiro, B. G., Hahn, R. C., Camargo, Z. P. D., \& Rodrigues, A. M. (2020). Molecular tools for detection and identification of Paracoccidioides species: Current status and future perspectives. Journal of Fungi, 6(4), 293. https://doi.org/10.3390/jof6040293

Roberto, T. N., Rodrigues, A. M., Hahn, R. C., \& de Camargo, Z. P. (2015). Identifying Paracoccidioides phylogenetic species by PCR-RFLP of the alphatubulin gene. Sabouraudia, 54(3), 240-247. https://doi.org/10.1093/mmy/myv083

Rodrigues, A. M., Kubitschek-Barreira, P. H., Pinheiro, B. G., Teixeira-Ferreira, A., Hahn, R. C., \& de Camargo, Z. P. (2020). Immunoproteomic analysis reveals novel candidate antigens for the diagnosis of paracoccidioidomycosis due to Paracoccidioides lutzii. Journal of Fungi, 6(4), 357 . https://doi.org/10.3390/jof6040357 
Research, Society and Development, v. 11, n. 3, e13911326152, 2022

(CC BY 4.0) | ISSN 2525-3409 | DOI: http://dx.doi.org/10.33448/rsd-v11i3.26152

Santos, A. R. D., Dionizio, A., Fernandes, M. D. S., Buzalaf, M. A. R., Pereira, B., Donanzam, D. D. F. A., ... \& Venturini, J. (2021). Proteomic analysis of serum samples of paracoccidioidomycosis patients with severe pulmonary sequel. PLoS neglected tropical diseases, 15(8), e009714. https://doi.org/10.1371/journal.pntd.0009714

Silva, M. J. A., da Cruz, E. C., Gama, G. C. B., \& Siqueira, A. S. (2021). Ecoepidemiologia da paracoccidioidomicose: Uma revisão narrativa da literatura. Research, Society and Development, 10(9), e31810918182-e31810918182. https://doi.org/10.33448/rsd-v10i9.18182

Sousa, J. A., Sá, R. S., \& Pereira, E. M. (2021). Consequências do diagnóstico tardio de paracoccidioidomicose: relato de caso. Jornal Brasileiro de Patologia e Medicina Laboratorial, 57. https://doi.org/10.5935/1676-2444.20210003

Shikanai-Yasuda, M. A., Mendes, R. P., Colombo, A. L., Queiroz-Telles, F. D., Kono, A. S. G., Paniago, A. M., ... \& Martinez, R. (2017). Brazilian guidelines for the clinical management of paracoccidioidomycosis. Revista da Sociedade Brasileira de Medicina Tropical, 50, 715-740. https://doi.org/10.5123/S167949742018000500001

Queiroz-Telles, F. V., Peçanha Pietrobom, P. M., Rosa Júnior, M., Baptista, R. M., \& Peçanha, P. M. (2020). New Insights on Pulmonary Paracoccidioidomycosis. Seminars in respiratory and critical care medicine, 41(1), 53-68. https://doi.org/10.1055/s-0039-3400544

Wagner, G., Moertl, D., Glechner, A., Mayr, V., Klerings, I., Zachariah, C., ... \& Willinger, B. (2021). Paracoccidioidomycosis Diagnosed in Europe-A Systematic Literature Review. Journal of Fungi, 7(2), 157. https://doi.org/10.3390/jof7020157 